\title{
Um passeio primaveril com Certeau: nas pegadas do cotidiano e da cultura
}

\author{
Paulo R. Souto Maior Júnior ${ }^{l}$ \\ paulosoutomaior@yahoo.com.br
}

Resumo: Este texto pretende fazer uma análise crítica e introdutória de algumas questões relativas às tramas do cotidiano e do entendimento da cultura na escrita do intelectual francês Michel de Certeau (1925-1986). Na concretização desta pesquisa lançamos mão da leitura do livro A invenção do cotidiano no volume "Morar, cozinhar" do qual será extraído reflexões acerca do ato de morar (espaço urbano) e de cozinhar (espaço privado); bem como $A$ cultura no Plural dando enfoque ao artigo "As universidades diante da cultura de massa" a fim de analisar as considerações certeaunianas acerca da cultura. Além do livro A escrita da História no qual analisamos as contribuições teóricas, sempre em nível introdutório, do texto "A operação historiográfica". Sem a colaboração metodológica de Alarcon Agra do Ó e Alípio de Souza Filho este passeio não teria sido possível.

Palavras-chave: Cotidiano - Cultura - Escrita da História - Michel de Certeau.

\section{1). Uma breve parada em (por) sua vida.}

Nascido em 1925 em Chabérry graduou-se em estudos clássicos e filosofia nas universidades de Grenable, Lyon e Paris.

\footnotetext{
${ }^{1}$ Aluno de Licenciatura em História - $7^{\circ}$ período na UFCG. e-mail: paulosoutomaior@yahoo.com.br.
} 
Além disso, se formou em Letras Clássicas, História e Teologia. Em 1950 entrou na ordem dos jesuítas (Companhia de Jesus) e em 1956 tornou-se padre. Neste mesmo ano fundou a revista Chritus. Doutorou-se em Teologia e conheceu a fama acadêmica ao publicar um artigo sobre o maio de 1968 na França.

Sua produção não era apenas em História. Eclético se aventurou na psicanálise, antropologia e linguística. Ora, percebe-se a importância na escrita de Certeau da inter e mutidisciplinaridade; intercâmbio capital, portanto, com outras áreas do saber. Não por acaso, a Escola Freudiana de Paris, fundada por Lacan, contou com Michel de Certeau desde a sua fundação em 1964

Ao dissertar sobre o presente torna-se referencial também na Sociologia. Esse interesse pelo outro é analisado numa perspectiva epistemológica de compreensão do não inteligível dentro de um discurso social e histórico, uma vez que transfere o "mesmo" para os campos da diferença, rompendo com o equilíbrio das certezas (Filho, 2002: 131).

Analisar as táticas cotidianas das minorias constituiu um dos mais ousados projetos. Transladou tais minorias para o estatuto de objeto de estudo, pensando como essas pessoas lidam com o poder através da resistência cotidiana. Não por acaso exercício de pensar o cotidiano observando as artes de fazer constitui modelo teórico em diversas áreas, especialmente quando se trata de estudar o outro. Desse modo, introduz um novo olhar que lemos partir de 
uma linguagem densa que convida o leitor a lê-lo associando-a um sem número de conhecimentos.

Lido por profissionais de diversas áreas das Humanidades é especialmente o historiador que Certeau seduz, pois, como escrever história sem pensar no que produz um filho de Clio ao escrever sobre ela? Como realizar uma "operação historiográfica"? Perguntas capciosas na sua própria imagem, mas da qual sabemos a necessidade dos procedimentos de análise, construção do texto e lugar de discurso na tentativa de respondê-las e escrever sobre Clio. Eis que o historiador se afasta de uma história global, caminha na beira do precipício, é atormentado por fantasmas do passado, mas está a todo instante envolto pela cultura. Ele a respira, a vive, se apaixona, discute com ela sempre na certeza de que ela é costurada no tecido do cotidiano. Destarte o que buscamos aqui é associar de maneira simples, porém eficaz a relação entre cultura e cotidiano na escrita certeuniana.

\section{2) Era uma vez... Entre árvores e luz do sol, Clio respira.}

No poema "Historiador", Drummond destaca:

Veio para ressuscitar o tempo e escalpelar os mortos, as condecorações, as liturgias, as espadas, o espectro das fazendas submergidas, 
Cadernos de Clio, Curitiba, n. ${ }^{\circ}$ 3, 2012

o muro de pedra entre membros da família, $\mathrm{o}$ ardido queixume das solteironas, os negócios de trapaça, as ilusões jamais confirmadas nem desfeitas.

O poeta propõe uma relação com o morto ao narrar sobre um "ressuscitar o tempo" onde é necessário "rasgar" os mortos, o passado de um modo geral, nas interfaces do viver e do morrer. Parece que o nosso poeta entende mesmo de história e poderia, talvez, por acaso, ter participado de um passeio primaveril com Michel de Certeau.

$\mathrm{Na}$ magia de construir o passado é preciso ousar. Para longe da cartola e da varinha de condão faz-se necessário a prática. Sem um aparato teórico será difícil tirar da cartola vazia um coelho ou transformar uma cédula de dois reais em uma de cem. Portanto, marca presença o historiador que busca não apenas o documento, deseja trabalhá-lo, compreendê-lo. Denominamos este ofício por? “O que fabrica o historiador quando faz a história?”(Certeau, 2010: $65)$.

Intrigante para alguns, estimulador para outros a noção de um trabalho técnico proposto por Certeau convida a pensar a atividade historiadora enquanto um operário. Uma atividade cheia de si no mecânico, no viril, no pronto (Albuquerque Júnior, 2009). O que é novo é a metodologia lançada pelo intelectual no texto 
Operação Historiográfica, longe da objetividade histórica e próxima das relatividades. Uma reflexão acerca do questionamento: "Quando a história se torna, para o prático, o próprio objeto de reflexão, pode ele inverter o processo de compreensão que refere um produto a um lugar?” (Certeau, 2010: 66) e da ciência histórica mais recente.

A atividade historiográfica não pode ter sucesso sem um espaço discursivo, uma disciplina e, por fim, a literatura daquilo que se estuda. Este é o esboço do seu texto e dos tópicos tratados.

O modelo subjetivo certeuniano só existe com um sistema de referência, conforme citado anteriormente. $\mathrm{O}$ trabalho do historiador só pode ser levado a cabo se se considerar um lugar posto que neste o profissional está enraizado numa série de peculiaridades as quais influenciarão nos métodos utilizados bem como nos interesses do trabalho por vir (Agra do Ó, 2004).

Analisar uma pesquisa sob a visão independente de uma instituição é quase impossível. Segundo Aron (Certeau, 2010: 67), um passo importante foi dado na "dissolução do objeto" ao retirar da história a pretensão de reconstituir a verdade ao pensar as relativizações num campo fechado. A operação historiográfica tem dois caminhos: reconstituir o passado é pincelar imagens "faltantes" e historicizar o presente.

Debruçado nas fontes, o historiador entra em contato com o infinito, o perene, uma relação múltipla de leituras acerca do 
passado. Ocorre que as mãos estão ansiosas em trabalhar o documento. Este seria estruturado, produzido de modo a atender estatutos da academia, fruto, pois, de uma prática social com ambivalência entre o escrito e o por ler. Logo emerge a questão do lugar do morto e o lugar do leitor. O morto é o passado com almas que insistem em alegrar o presente. A narratividade dos mortos demarca um lugar para os vivos. A historiografia tem o morto como personagem principal. Sem ele não há história. A escrita é um sepultamento sem adeus e arriscando na visão machadiana uma "defunta autora", preocupada em situar a partir de sua função simbólica, em descartar o passado a partir do seu referencial ser o presente, permitindo a existência dos vivos a partir dos mortos (Agra do Ó, 2004).

"A história começa senão com a 'nobre palavra' da interpretação" (Certeau, 2010: 78), a frase é do nosso autor e a ideia dos Annales. Neste campo a técnica delimitaria um segundo passo no caminho produzido na socialização do ir e do vir, permitindo ao historiador trabalhar a prática e iniciar a pesquisa, uma, abusando do autor, "fronteira mutável entre o dado e o criado" (Certeau, 2010: 78)

O documento é trabalhado seguindo dois fatores: primeiro, uma metodologia do universo acadêmico; segundo, os objetos que dispõe para fazer a análise, dentre os quais a própria fonte. Concluída a operação uma história foi construída, uma alternativa 
para o passado. Pergunta o leitor: um texto pronto e definitivo? Jamais, talvez a única certeza na história seja da pluralidade da narrativa, porque, descontente com o pronto e inacabado, ela quer se renovar, precisa de outro ambiente, ela é e insiste e ser nômade e mutável. Alterar-se é o seu foco. Porém alterar-se em razão de quê? O passado no documento é um produto, uma fabricação disponível a diversos olhares e interpretações.

Certeau propõe a relação das fontes com um lugar, um aparelho e uma técnica, mesmo que seja preciso mudar estratégias no ato de dar movimento a um óleo sobre a tela sempre imóvel que é o passado. Tais fontes poderão ser usadas de outra forma, para tanto o mesmo ocorrerá com a escrita que advém dela. Modificação capital se se objetiva uma história nova e novas histórias. E, por conseguinte, permite refletir "o que é que o historiador fabrica quando se torna escritor? Seu próprio discurso deve revelá-lo?" (Certeau, 2010: 96)

A escrita histórica é uma representação relacionada ao lugar social sob influência de uma cultura. Se não for assim não será narrativa histórica. Certeau coloca os limites circunscritos entre narrativa histórica e literária, isto é, a necessidade da primeira usar uma fonte, se remeter a um significado, a segunda, pelo contrário, se constrói na ficção.

A narratividade é filha das suas práticas cuja relação maior não seja talvez com o seu autor, o leitor é o clímax. Este tem um 


\section{Cadernos de Clio, Curitiba, n. ${ }^{\circ}$ 3, 2012}

espaço subjetivo que permite o intercruzamento de ideias. Sabe-se coveiro do tempo. Mais! Pode sofrer influências das tramas com as quais lida, ou do próprio texto, no caso o autor da mesma forma, pode distorcer as técnicas de análise, o discurso se opõe a prática corroborando uma inversão escriturística.

O tempo casa-se com a história e a cronologia se insere com ciúmes ao delimitar os períodos. O autor se perturba, pois remando contra a maré vai do presente ao passado. A bússola é certa no destino do escrito. Seu porto,como já colocado, é o leitor. $\mathrm{O}$ desembarque traz uma nova poética, uma colaboração ao entendimento de nós mesmos.

\section{3) Sobre morar e cozinhar: agora uma cotidianidade concreta.}

Após o tomo I A invenção do cotidiano "Artes do fazer" que traz reflexões para uma adequada "operação historiográfica" em que mostra as influências de Freud, Bourdieu, Wittgenstein, Foucault, entre outros, e novos conceitos para o trabalho do historiador. Michel de Certeau só teve tempo para poucas publicações antes de sua morte (1986), nesse entretempo foi relativamente pequeno (em termo de escrita própria) o seu trabalho no tomo II A invenção do cotidiano "Morar, cozinhar", mas como aprendizes fiéis de M. de Certeau o livro é resultado dos trabalhos de Pierre Mayol e Luce Giard que se voltaram ao espaço urbano 
(bairro, morar) e ao espaço privado (cozinha, cozinhar) respectivamente.

Os estudos de Certeau são habitados pelos homens ordinários, que conferem sentido às suas habilidades e práticas elaborando artes de fazer em determinado lugar que é "aquilo que nos é dado a cada dia (o que nos cabe em partilha), nos aprisiona a cada dia (Certeau, 1996: 31). Um dos olhares para a ação dos homens comuns será pautado no bairro e na cozinha, conforme encontramos no tomo II

E, como apontou Certeau, Pierre Mayol e Luce Giard foram no dia-a-dia, dentro de um sistema de referências, recortar experiências e proporcionar a nós leitores a possibilidade de uma pesquisa onde as maneirar de fazer encontram uma cotidianidade concreta. Estudando essa relação teoria-prática o historiador irá dialogar com outros campos do saber, por consequência com outros sujeitos do pensamento e com isso há uma ampliação do universo historiográfico que transformará a sua visão quanto à ação cultural, política ou sócio-econômica de uma determinada prática em um determinado lugar social.

Partindo para as maneiras de fazer, trazidas pela dupla no tomo II, ao lermos fica provada que a ideia de Certeau, a de experimentação controlada na ordem do pensável, foi posta em prática; narrar, confrontar e caracterizar essas atividades de natureza corriqueira, elaborando "uma ciência da prática singular" são 
atividades trazidas a nós através desses escritos como métodos de pesquisa, por exemplo, quanto à escolha e manuseio do lugar social:

Deste modo, aos poucos se foi construindo um afastamento controlado e controlável de nossos lugares e de nossas práticas de vida, a fim de podermos espantar-nos com eles, interrogá-los e depois dar-lhes sentido e forma em uma espécie de "nova criação" conceitual (Certeau, 1996, p.23) .

Comecemos por Pierre Mayol e o morar, cartografando o bairro, Mayol elucidará a maneira de morar na cidade e as práticas culturais de usuários do mesmo, tomado por duas vertentes, a sociologia urbana do bairro e a análise sócio-etnográfica da vida cotidiana. Para isso, Mayol utiliza dados estatísticos, dialoga com conceitos de arquitetura, por exemplo, e realiza pesquisas relacionadas à cultura popular.

O bairro foi escolhido por ser território em que ocorre uma "encenação da vida cotidiana", de modo que há espaço público e privado ao mesmo tempo, como os usuários dominam essa separação de espaços, quais "táticas" utilizam pra isso, são questões fundamentais do estudo de Mayol. Como amostra de ideal certeauniano tem aqui novos problemas, novas abordagens e novos objetos. Como problemáticas temos o comportamento dos integrantes do bairro, especialmente o visível, os componentes da rua, entrando então as vestimentas, os códigos de cortesia e valorização de determinado espaço público; Mayol traz, então, 
Cadernos de Clio, Curitiba, n. ${ }^{\text {o } 3,} 2012$

hipóteses e conceitos, como o de conveniência, que através de contribuições individuais há a melhora coletiva, por haver benefícios simbólicos em jogo.

Um dos muitos proveitos que um historiador pode pensar desse estudo é a compreensão do que é "prática cultural", isto é, em breves palavras, comportamentos cotidianos que se traduz numa esfera maior, a social. Permitindo achar a identidade admitindo um lugar na rede social de relações, está localizado o pódio dos usuários e/ou grupos sociais. A prática do bairro (espaço de relação com o outro como ser social, 1996: 43), deixa claro Mayol, depende de uma tática que tem por parte "o lugar do outro".

Com esses conceitos-chave o que se passa no bairro da Croix-Rousse, na rua Rivet e no comerciante Robert já podem então serem estudados como práticas singulares a se tornarem vivas e não mais anônimas.

Percorrendo o ambiente privado, Luce Giard escreve outra aula de métodos para produção historiográfica do tomo II, adotando como base a noção de "observação participante" Giard em seu Intróito (1996: 212) deixará claro a sua relação (experiência) e semelhança ao seu objeto de estudo.

A pesquisa de Giard apresentará o papel das mulheres na preparação da comida no lar (embora ela atente que esta condição não é só feminina por natureza), situação do terreno sócio-cultural e objeto das mentalidades nos estudos franceses até os idos de 1980. 
Além disso, seu olhar nos fará refletir em como os hábitos alimentares estabelecem a relação entre um passado e um presente que se encontram e que possuem ritos que utilizam a imaginação e memória como mecanismos úteis ao fazer historiográfico.

Giard pautará em cima dessa prática diversas hipóteses (afinal uma das funcionalidades que se tem ao determinar um terreno é a de exercício de hipóteses), em um primeiro momento analisa a ação cozinhar como típica a mulheres, pondo a mostra práticas comuns ao ambiente e ao ato, como o de aprender teoricamente a cozinhar (livros de gastronomia), lembrar gestos que estão na memória vinda da infância, o prazer em preparar receitas, enfim, saberes pessoais constituindo um terreno de possibilidades para a História Cultural.

Apoiando-se em Lévi-Strauss ela trará conceitos do ser ou não comestível, misturas de ingredientes, formas distintas de preparo das receitas, bons modos à mesa e privações alimentares provisórias. Já em Bourdieu, Giard toma de empréstimo a opinião de diferentes gostos e formas de apreciação. Para elaboração de seu estudo, ela realizou entrevistas com amigas e familiares, conversas informais, utilizou conceitos da nutrição.

Como "o que interessa ao historiador do cotidiano é o invisível" (1996: 31) Pierre Mayol e Luce Giard olharam justamente o que nos é obscuro, que faz parte de um grupo anônimo que pratica o ordinário, como um simples cumprimentar ao vizinho 
Cadernos de Clio, Curitiba, n. ${ }^{\text {o }}$ 3, 2012

na rua do bairro ou escolher e preparar receitas gastronômicas, é precisamente o que nos traz a mensagem do fim do livro.

\section{4) Um plural chamado cultura.}

Mas o que seria a cultura para Michel de Certeau? Segundo ele, a cultura "não consiste em receber, mas em realizar o ato pelo qual cada um marca aquilo que outros lhe dão para viver e pensar" (Certeau, 1974: 9), ou seja, cada indivíduo vai significar, ou melhor, ressignificar aquilo que o meio social disponibiliza, sendo a cultura verdadeiramente existente quando os praticantes desta dão sentido para aquilo que realizam. Nesse caminho, Certeau quebra com a ideia de uma cultura própria de um grupo de "eleitos", a chamada cultura letrada, mostrando que não há uma cultura monolítica, mas uma pluralidade de culturas, isto é, um sistema de referências e significados heterogêneos entre si.

Numa perspectiva certeauniana, toda cultura requer a ação de uma atividade, com transformações pessoais, fazendo com que cada época tenha algo próprio e específico. Dessa forma a cultura deve ser colocada como algo que sempre está se modificando, se reinventando, não devendo ela ser protegida ou defendida como um patrimônio, e sim realizada em toda a sua extensão da vida social.

Ao expor essas ideias sobre cultura, Certeau termina por escolher um caminho contrário no qual todos estavam acostumados, pois ele desmistifica aquela cultura considerada única, fechada, 
elitizada, ou seja, a "cultura no singular", que era imposta e traduzia o meio. Ele prefere substituí-la por outra concepção, a "cultura no plural", termo que dá nome a um de seus livros.

O livro "A Cultura no Plural" foi publicado pela primeira vez em 1974, ele é fruto da reunião de uma série de artigos isolados publicados entre 1968 e 1973. Com lucidez e precisão Certeau fala sobre a vida social e a inserção da cultura nessa vida. Tendo chegado a esse campo de estudo em maio de 1968, quando era redator da revista Études, um periódico mensal de cultura geral, publicado pela Companhia de Jesus. Nesse momento Certeau havia comentado os fatos, no calor do momento, através de artigos que ficaram famosos e fez com que ele recebesse vários convites para colaborar em diversas áreas de discussão e pesquisa, desde encontros informais, à assessoria de diversos ministérios.

Esses intercâmbios trouxeram ao historiador em questão um aprofundamento das suas reflexões, desviando seu olhar do abismo das generalizações e dos lugares comuns que insistiam em aparecer na história cultural. Isso terminou por gerar os textos que estão no livro "A cultura no plural", dentre eles será analisado o artigo "As universidades diante da cultura de massa", com o intuito de trazer um pouco mais daquilo que foi pensado por Certeau acerca da cultura.

Nesse artigo, Michel de Certeau quer fazer pensar a situação das universidades francesas, que, naquele período, viviam 
um momento de massificação, e, dessa forma, deveriam se adequar a nova situação a qual se encontravam. Logo no início de suas palavras Certeau pontua que "a universidade deve solucionar atualmente um problema para o qual sua tradição não o preparou: relação entre a cultura e a massificação de seu recrutamento" (Certeau, 1974: 101). Esse despreparo das universidades se dá pelo fato de que até pouco tempo elas transmitiam uma "cultura de elite", sendo proibida para alguns e própria de um grupo, que foi previamente selecionado pelo meio social.

Sendo necessário ressaltar que a relação da cultura com a sociedade modificou, pois ela não está mais reservada a um grupo social específico ou algo particular de certos profissionais, ou seja, a cultura não está fechada em um único referencial aceito por todos. Essa transformação foi impulsionada pelo aumento demográfico e a elevação do nível de vida das pessoas, gerando uma crescente participação cultural e social, além de uma maior entrada da classe média no ensino superior. Dito isto, para o historiador em questão não basta que as universidades apenas melhorem suas estruturas, aumentem o corpo docente ou façam mais faculdades, é necessário que haja a solução dos problemas internos.

Essa nova realidade, segundo Certeau, gerou dois tipos de atitudes por parte das universidades. Umas procuram proteger-se, tornando-se mais rígidas, com a chamada política do "não nos renderemos", outras se apóiam na "mistura" e na discussão para 
elaboração de uma linguagem cultural nova, mas terminavam por cair na incompetência. Nesse sentido, se torna imprescindível que as universidades mudem e se façam a partir desse novo fato, produzindo intelectualmente aquilo que seja relevante, ou melhor, aquilo que tenha um significado e estejam ligados com aqueles que o produzem (Certeau, 2004; 113).

Para que as universidades possam superar esse problema, é preciso que elas entendam que a língua não pode ser mais vista no seu sentido único, fixado por um código acadêmico e atentar para existência de uma cultura anômica, fruto de colagens e justaposições, não conseguindo o aluno organizar as informações recebidas. Associada a isso está a pertinência do ensino. Dessa forma, a universidade é vista como apenas um meio de alcançar uma profissão e conseguir um diploma, sem haver aqueles investimentos maiores no saber. Esses problemas terminam gerando o que Certeau chama de "fixismo nostálgico", onde o docente se fecha e tenta preservar os antigos valores da academia, recusando essa pluralidade de culturas. Diante disso, Michel de Certeau propõe um ensino que não consistiria na exposição de saberes estabelecidos, mas na aprendizagem de métodos, numa prática de textos, sendo este um ato produtor, onde a universidade iria formar um espaço crítico, tendo professores e alunos elaborando uma prática própria de informação. 
Nas suas palavras finais Certeau diz que "O que requer a introdução da cultura de massa na universidade é o nascimento do trabalhador estudante e do trabalhador docente, a abolição da divisão social do trabalho. 'É preciso, pois, que cada docente admita por si mesmo a necessidade de ir buscar seu saber alhures e que, para isso, faça algo diferente." (Certeau, 1974: 115). Ou seja, os saberes seriam construídos numa parceria docente e aluno, com as partes em pé de igualdade e contribuição.

\section{5) Reflexões ao por do sol.}

Voltamos desse breve passeio com a mala fervilhando de inquietações. Nessa caminhada ao lado de Certeau percebeu-se que é necessário que o Historiador se debruce sobre suas obras, uma vez que as novas abordagens surgidas com o movimento dos Annales, a exemplo, das pesquisas na vida cotidiana e na nova história cultural, precisaram ser reanalisadas no seu viés principal. A cultura para Certeau não estava restrita à elite, mas ao conceito plural desse termo. Além de perceber que a cultura se faz no cotidiano, sendo sempre uma atividade, um fazer, que está ao decorrer do tempo se ressignificando, reelaborando. Apesar de muitas vezes Certeau ser considerado de difícil entendimento, por causa de sua escrita "rebuscada", seu pensamento é simples, mas de muita relevância. Seria desonesto ainda não mencionar, ao menos sob a forma de análise, a colaboração que Foucault desempenha nos estudos 
certeaunianos. Só se fala em tática porque Foucault falou de poder e de subjetividades. Michel de Certeau desenvolve alguma dessas ideias sendo dessa forma atual aos pesquisadores.

Em meio a esta andança na companhia de Certeau, fica claro: o historiador quando escreve a história realiza a produção de um lugar. Debruça-se sobre fontes, diversos objetos, temáticas como o ambiente, as vestimentas, o cotidiano, a cultura, o lixo, a água e os transformam, metamorfoseiam-nos em história. Esta "ciência" não quer-se finita, pronta, acabada. Almeja, do nada, entrar em erupção, causar polêmica, regravar nomes que certamente se perderam à-toa. Toma para si mesma o que Drummond tão bem expressou na Literatura:

Veio para contar o que não faz jus a ser glorificado e se deposita, grânulo, no poço vazio da memória. É importuno, sabe-se importuno e insiste, rancoroso, fiel.

\section{Referências Bibliográficas:}


ALBUQUERQUE JÚNIOR, Durval Muniz de. O Tecelão dos Tempos: o historiador como artesão das temporalidades. In: BELINI, Ligia e NEGRO, Antônio Luigi. Tecendo Histórias: Espaço, política e identidade. Salvador: EDUFBA, 2009.

CERTEAU, Michel de. A Invenção do Cotidiano I: artes de fazer. Petrópolis Vozes, 1996.

; GIARD, Luce \& MAYOL, Pierre. A Invenção do Cotidiano 2: Morar, Cozinhar.

; A Cultura no Plural. São Paulo: Papirus, 1995.

; A operação historiográfica. In: A Escrita da Historia. Rio de Janeiro: Forense Universitária, 1982, PP.56-107.

DO Ó, Alarcon Agra. Michel de Certeau e a Operação Historiográfica. Veredas FAVIP, Caruaru, v.1, n.2, p.48-56, 2004. FILHO, Alípio de Sousa. Michel de Certeau: Fundamentos de uma sociologia do cotidiano. Sociabilidades (USP), São Paulo/ sp, v.2, p.129-134, 2002. 